\title{
AN ADAPTIVE WEB-BASED LEARNING ENVIRONMENT FOR THE APPLICATION OF REMOTE SENSING IN SCHOOLS
}

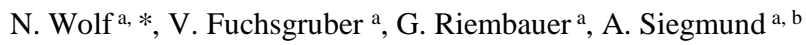 \\ a Dept. of Geography, Heidelberg University of Education, Germany - (nils.wolf, fuchsgruber, riembauer, siegmund)@ph- \\ heidelberg.de \\ ${ }^{\mathrm{b}}$ Heidelberg Center for the Environment (HCE), Heidelberg University, Germany
}

Commission VI, WG VI/2

KEY WORDS: adaptive learning, remote sensing education, web-based learning platform, remote sensing in schools

\begin{abstract}
:
Satellite images have great educational potential for teaching on environmental issues and can promote the motivation of young people to enter careers in natural science and technology. Due to the importance and ubiquity of remote sensing in science, industry and the public, the use of satellite imagery has been included into many school curricular in Germany. However, its implementation into school practice is still hesitant, mainly due to lack of teachers' know-how and education materials that align with the curricula. In the project "Space4Geography" a web-based learning platform is developed with the aim to facilitate the application of satellite imagery in secondary school teaching and to foster effective student learning experiences in geography and other related subjects in an interdisciplinary way. The platform features ten learning modules demonstrating the exemplary application of original high spatial resolution remote sensing data (RapidEye and TerraSAR-X) to examine current environmental issues such as droughts, deforestation and urban sprawl. In this way, students will be introduced into the versatile applications of spaceborne earth observation and geospatial technologies. The integrated web-based remote sensing software "BLIF" equips the students with a toolset to explore, process and analyze the satellite images, thereby fostering the competence of students to work on geographical and environmental questions without requiring prior knowledge of remote sensing. This contribution presents the educational concept of the learning environment and its realization by the example of the learning module "Deforestation of the rainforest in Brasil".
\end{abstract}

\section{INTRODUCTION}

Satellite images can stimulate the students' motivation, improve their understanding of Earth system processes and convey geospatial thinking and technical skills. The competences to interpret and analyse satellite images are represented in Germany's national education standards and a growing number of federal curricula (DGfG 2007; KMK 2015). Also, empirical studies show the high interest, learning efficacy and motivation of students when analysing satellite images (Ditter 2013; Siegmund 2010). Nevertheless, the implementation of satellite images into school teaching is generally hesitant (Voss 2011; Pingold 2013). Most often the application in school lessons only comprises the visual analysis of true colour images, not exploiting the full potential of satellite images. Reasons for this gap are the complexity of remote sensing and its applications as well as the lack of expert knowledge of teachers (Ditter et al. 2012). Within the project "Space4Geography" a learning platform is developed, offering ten learning modules on key issues of geography education that can be easily implemented in geography lessons. The students work on environmental questions with the integrated web-based remote sensing software "BLIF". The platform's development is scientifically accompanied by two dissertation projects, focusing on the identification of general design principles for the platform and the evaluation of different implementations of adaptive learning regarding.

\section{EDUCATIONAL CONCEPT}

For a successful implementation of remote sensing in school lessons, an activity and problem oriented educational concept (Michel, Voss 2013; Krautter 2015; Kestler 2015) is realized. The concept aims the straightforward and useful embedding of satellite images and remote sensing methods into school teaching. The key features and intentions are:

- To introduce young people into the versatile application areas of optical as well as active satellite imagery (RapidEye and TerraSAR-X).

- To convey content that is up-do-date, relevant and presented with a superordinate geographic question.

- To increase interest of the students by age-appropriate story-telling, identification figures and linkages to the everyday life (Wütherich 2013).

- Selection of topics based on a systematic analysis of the current curricula of Germany's federal states (see www.rgeo.de/bpa) to support the nationwide straightforward embedding into school teaching.

- Learning modules are designed to be completed within double lessons (90 minutes).

- Optimized presentation of the learning content for the use on both desktop and table computers to allow a more flexible implementation in the classroom.

- Learning management functions are provided to support the teachers in investigate their students' performances.

\footnotetext{
* Corresponding author
} 
To make the learning more effective, the modules support personalized learning paths, enabling the real-time adaption of content and level of difficulty depending on the student's competencies (cp. Figure 1). This approach seeks to overcome the known limitations of traditional one-size-fits-all approaches which neglect the heterogeneity of the learner group. By working on interactive tasks (multiple-choice questions, allocation quizzes etc.) the level of knowledge of the student is assessed and further information appropriately adapted.

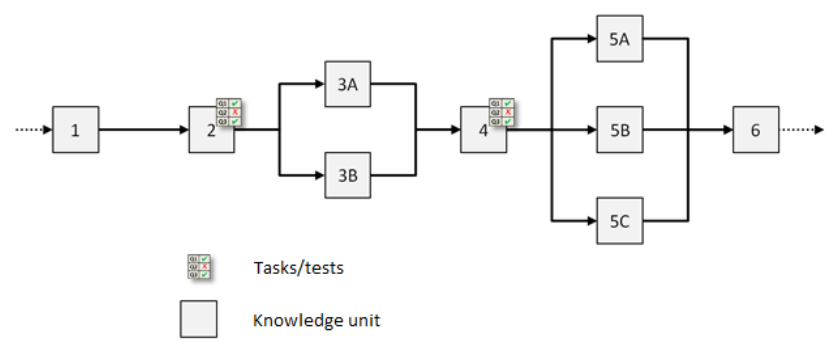

Figure 1. Adaptive learning to support individual learning paths.

The core element of each learning module is the analysis of satellite images which are implemented at several points to impart knowledge about the topic. Then students work with the original data to explore the geographic question. For this purpose, the web-based remote sensing software "BLIF" is integrated into the learning module.

\section{THE LEARNING MODULE "DEFORESTATION OF THE RAINFOREST IN BRASIL"}

The practical realization of the educational concept is presented by the example of the learning module "Deforestation of the rainforest in Brasil" which is designed for the application in geography classes or related subjects at the grade levels seven and eight. Rainforests/tropics is a popular topic in German curricula in these grade levels (KMK 2015) and, at the same time, it is well represented in public media. The assessment of (illegal) deforestation, as an important application area of remote sensing, is exemplified in the learning module by using high-resolution optical satellite data of the RapidEye constellation.

Following the storyline of "Arty" the macaw, the identification figure, students learn about the global distribution of rainforests, their biodiversity and economic use (Figure 2). Connecting resources from the rainforest to the globally distributed products, the connection to the students' everyday life is built. The irreversible loss of rainforests and their biodiversity is presented and discussed as a major threat facing our society. Moreover, the effects of deforestation on the global climate are made subject of discussion.

The knowledge units comprise information on deforestation and an interactive map to explore deforested areas between 2000 and 2013. Interactive tasks and knowledge checks are implemented at several points to assess the students' performances an acquire data to be used for the adaptive allocation of content (see Figure $2 b$ ).

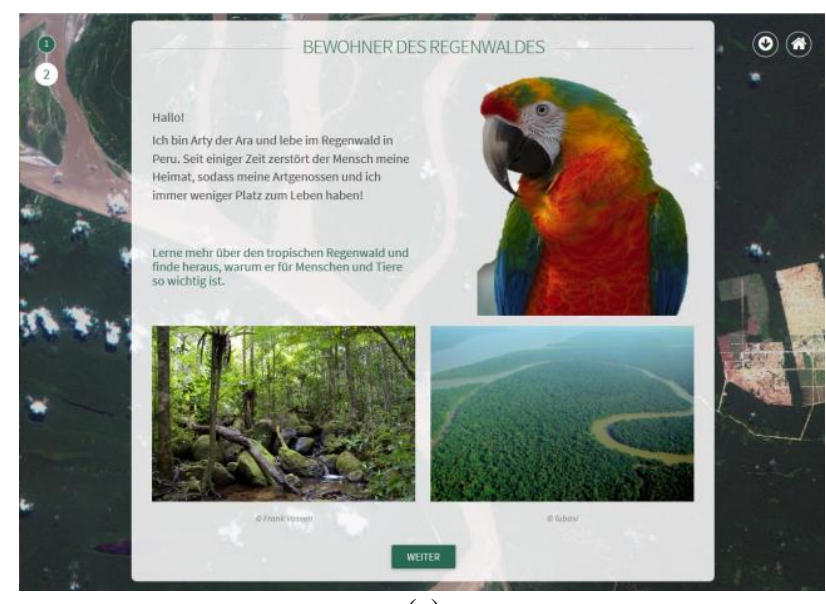

(a)

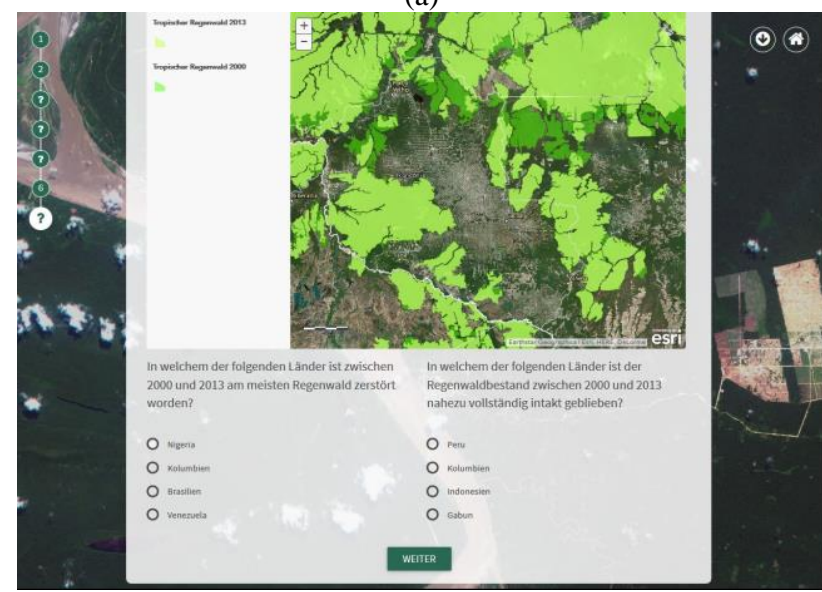

(b)

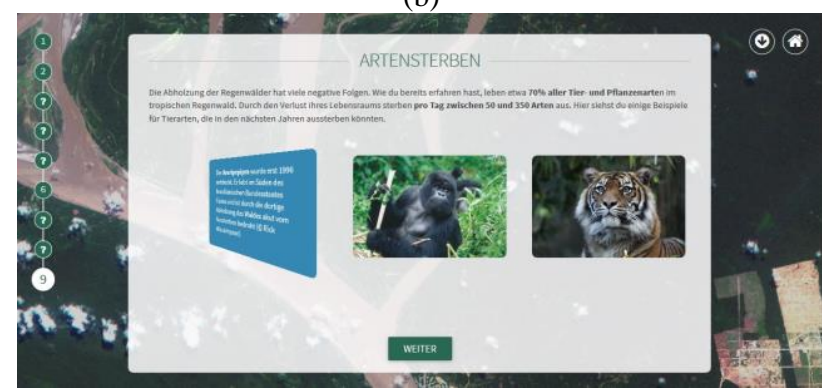

(c)

Figure 2. Screenshots showing some exemplary knowledge units of the learning module "Deforestation of the rainforest in Brasil".

Satellite images as a tool for the assessment of illegal deforestation are introduced with several examples of the Amazonian rainforest. Using sliders, temporal comparisons are carried out, focussing on visual analysis of the shape and position of deforested areas. These images familiarize the students with the view from above and structures of deforestation. Using "BLIF", students investigate whether the official deforestation rate was exceeded in Peru.

Finally, students obtain a personalised certificate showing their overall result from the interactive tasks and knowledge checks.

The web-based remote sensing software "BLIF" is implemented within the learning module but is also available as standalone version. An updated release includes a modernized, responsive interface and technical reworks. The students perform main (pre-)processing steps of satellite image analysis such as histogram stretching, image enhancement, colour composites, 
vegetation indices (Normalized Differenced Vegetation Index, Ratio Vegetation Index), unsupervised (k-means) and supervised (Maximum Likelihood) classification and change detection. Supported sensors comprise Landsat 5-8, RapidEye and TerraSAR-X. For the analysis of active sensor systems the functions to calculate speckle and threshold filtering algorithms are included. Different user modes from beginners to experts adapt to the students prior experience.

Within the learning module, students explore the location of the provided RapidEye dataset with an OpenStreet-Map Layer (Figure 3).

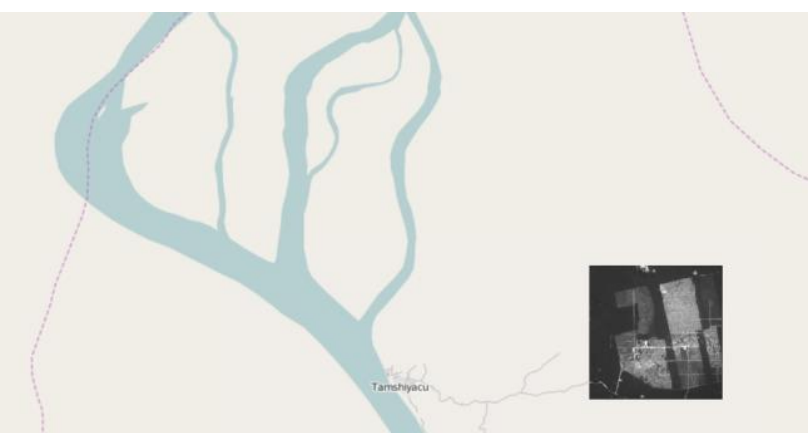

Figure 3. "BLIF" function for the localisation of the RapidEye scene.

They can perform an automated contrast enhancement and manually adjust brightness and contrast. A change detection is carried out by calculating a supervised classification for two images from 2012 and 2014. The results can be compared visually with interactive viewer functions, e.g. to adjust the transparency of individual layers, and can also be quantified with the tabular information about relative and absolute frequency of pixels in each class (Figure 4).

For each learning module, the platform offers further satellite scenes enabling the student to transfer and apply the developed competencies and technical skills within a new geographic region.

\section{SUMMARY AND OUTLOOK}

This contribution introduces the learning module "Deforestation of rainforest in Brasil", developed within the project "Space4Geography" which seeks at implementing satellite images in schools. This example demonstrates the opportunities of a problem-oriented application of remote sensing as a modern method of geography teaching. The platform will be evaluated with approximately 800 students in the frame of the "GIS-Station, Klaus-Tschira-Competence Centre for digital Geomedia" at the Department of Geography - Research Group for Earth Observation ( $\left.{ }^{\mathrm{r}} \mathrm{geo}\right)$ of the Heidelberg University of Education as well as at the DLR_School_Lab in Oberpfaffenhofen of the German Aerospace Center. The learning platform including the revised learning modules will be freely available in September 2016.

\begin{tabular}{|l|l|l|l|l|}
\hline \multicolumn{2}{|l|}{ Klasse } & Name & Absolute Häufigkeit & Relative Häufigkeit \\
\hline \multirow{2}{*}{ Klasse 1 } & Regenwald & 988624 & 1.00 \\
\cline { 2 - 4 } & & Plantage & 3392 & 0.00 \\
\hline
\end{tabular}

\begin{tabular}{|c|l|l|l|l|}
\hline \multicolumn{2}{|l|}{ Klasse } & Name & Absolute Häufigkeit & Relative Häufigkeit \\
\hline & Klasse 1 & Regenwald & 511341 & 0.52 \\
\hline & & Plantage & 478684 & 0.48 \\
\hline
\end{tabular}

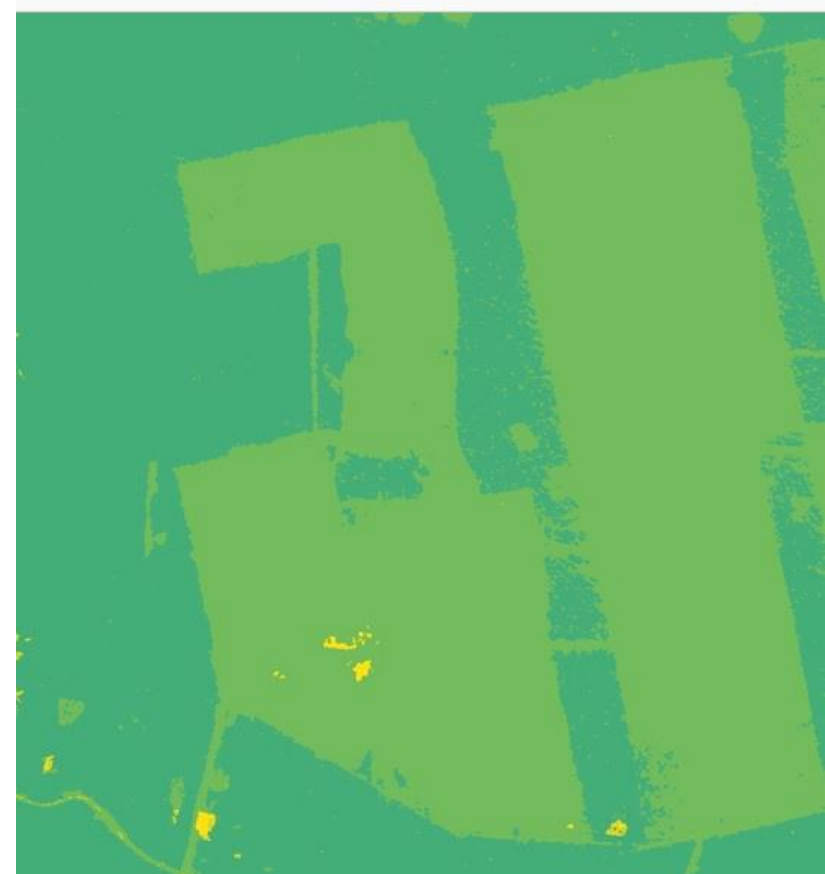

Figure 4. "BLIF" results of the change detection including absolute and relative frequency of pixels.

\section{ACKNOWLEDGEMENTS}

The project "Space4Geography" is funded by the German Aerospace Center (Space Administration).

\section{REFERENCES}

Ditter, R., 2013. Die Wirksamkeit digitaler Lernwege in der Fernerkundung. Eine empirische Untersuchung zu Lernmotivation und Selbstkonzept bei Schülerinnen und Schülern der Sekundarstufe. Heidelberg University of Education.

Ditter, R., Michel, U., Siegmund, A., 2012. Neue Medien Möglichkeiten und Grenzen. In Johann-Bernhard Haversath (Ed.). Geographiedidaktik, Westermann.

Kestler, Franz, 2015. Einführung in die Didaktik des Geographieunterrichts: Grundlagen der Geographiedidaktik und ihrer Bezugswissenschaften. Julius Klinkhardt, Bad Heilbrunn.

KMK, 2015. Bildungspläne/Lehrpläne der Länder im Internet. Kultusministerkonferenz. Available online at 
http://www.kmk.org/dokumentation/lehrplaene/uebersichtlehrplaene.html, checked on 1/13/2016.

Krautter, Y., 2015. Medien im Geographieunterricht nach lernförderlichen Kriterien auswählen. In Sybille Reinfried, Hartwig Haubrich (Eds.). Geographie unterrichten lernen. Die Didaktik der Geographie. Berlin, Cornelsen.

Lillesand, T. M., Kiefer, R. W., 1979. Remote sensing and image interpretation. Wiley.

Michel, U.; Voss, K., 2013. Fernerkundung. In Dieter Böhn, Gabriele Obermaier (Eds.). Wörterbuch der

Geographiedidaktik. Begriffe von A-Z. Braunschweig, Westermann.

Pingold, M., 2013. Luft- und Satellitenbilder. In Dieter Böhn, Gabriele Obermaier (Eds.). Wörterbuch der

Geographiedidaktik. Begriffe von A-Z. Braunschweig, Westermann.

Siegmund, A., 2010. Satellitenbilder im Unterricht - eine Ländervergleichsstudie zur Ableitung fernerkundungsdidaktischer Grundsätze. Pädagogische Hochschule Heidelberg, Heidelberg. Available online at http://opus.bsz-

bw.de/phhd/frontdoor.php?source_opus=7524\&la=de, checked on $1 / 15 / 2016$.

Voss, K., 2011. Fernerkundung - ein Thema für den modernen Geographieunterricht. In Praxis Geographie (11), pp. 14-17.

Wütherich, C., 2013. Methodik des Geographieunterrichts.

Westermann, Braunschweig. 